\title{
General Psychiatry Electroconvulsive therapy, catatonia, deep vein thrombosis and anticoagulant treatment: a case report
}

\author{
Ana Pérez-Balaguer (10 , Irene Sánchez-Rivero
}

To cite: Pérez-Balaguer $A$, Sánchez-Rivero I.

Electroconvulsive therapy, catatonia, deep vein thrombosis and anticoagulant treatment: a case report. General Psychiatry 2021;34:e100666. doi:10.1136/ gpsych-2021-100666

- Additional supplemental material is published online only. To view, please visit the journal online (http://dx.doi.org/10.1136/ gpsych-2021-100666).

Received 28 September 2021 Accepted 06 December 2021

Check for updates

C Author(s) (or their employer(s)) 2021. Re-use permitted under CC BY-NC. No commercial re-use. See rights and permissions. Published by BMJ.

Department of Psychiatry, Hospital Universitario Puerta de Hierro Majadahonda, Majadahonda, Spain

Correspondence to Dr Ana Pérez-Balaguer; anaperezbalaguer@gmail.com

\section{ABSTRACT}

Electroconvulsive therapy (ECT) is considered an effective treatment for pharmacotherapy-resistant severe mental disorders. Catatonia is a complex syndrome characterised by important psychomotor disturbances. Deep vein thrombosis (DVT) and pulmonary embolism (PE) are frequent side effects of prolonged immobility in catatonic patients. Therefore, it is important to resolve the catatonia as soon as possible. ECT is the most effective therapy available and is generally considered a safe procedure. Nevertheless, its use in patients with DVT or $\mathrm{PE}$ and anticoagulant treatment remains controversial. We describe a case of a woman in her 40s with a previous diagnosis of bipolar disorder and dysfunctional personality traits. She was hospitalised with persecutory and reference delusions, high emotional lability, anxiety, somatisation and regressive conduct. She later developed catatonic symptoms. No progress was achieved after a month of hospitalisation, despite several pharmacological treatments. She suffered multiple complications of prolonged bedding, such as an extensive DVT of the left common femoral, the external iliac and the common iliac veins. ECT was conducted under treatment with bemiparin. After the third administration, she showed improvement. No major bleeding or PE was developed. The safety of ECT while receiving anticoagulant therapy has been documented, though dosage and type of anticoagulant must be considered. Location of DVT (proximal or distal) may be an important topic to take into account. This report provides further evidence about the efficacy and safety of undergoing ECT in the context of concomitant serious medical conditions, such as DVT and anticoagulant therapy administration.

\section{INTRODUCTION}

Electroconvulsive therapy (ECT) might improve pharmacotherapy-resistant, severe mental disorders such as depression, mania, schizophrenia or catatonia, regardless of the underlying diagnosis. ${ }^{12}$

Catatonia is a complex syndrome characterised by a considerable psychomotor disturbance, which may range from marked unresponsiveness to marked agitation. Clinical presentation may include stupor, catalepsy, waxy flexibility, mutism, negativism, posturing, stereotypies, echolalia or echopraxia. It can occur in the context of various mental disorders and other medical conditions. ${ }^{3}$ Catatonic patients often experience prolonged periods of immobility, increasing the risk of blood stasis and, as a result, deep vein thrombosis (DVT) or a pulmonary embolism (PE). Other complications, such as decubitus ulcer, rhabdomyolysis, infections, urinary retention and flexion contractures, might also occur. Therefore, it is important to resolve the catatonia as soon as possible. ${ }^{24}$

Although ECT is generally considered a safe and effective procedure for catatonic symptoms, ${ }^{12}$ its use in patients with DVT and anticoagulant treatment is still controversial. ${ }^{25}$ To provide further evidence on this topic, we report the case of a patient who presented with catatonic symptoms and extensive DVT. ECT was conducted under anticoagulation treatment, ultimately resulting in the patient showing improvement and without developing any complications.

\section{CASE REPORT}

The patient was a woman in her 40s, with a previous diagnosis of bipolar disorder and dysfunctional personality traits. She also suffered from fibromyalgia, chronic fatigue syndrome and generalised spondylarthrosis. She had two previous admissions and an outpatient follow-up since 2001 and a history of multiple psychopharmacological treatments. She was hospitalised with persecutory and reference delusions, emotional lability, anxiety, somatisations and regressive conduct. She referred to autolytic ideas, owing to her illnesses, ailments and physical limitations. At admission, she was taking quetiapine 500 $\mathrm{mg}$, topiramate $50 \mathrm{mg}$, lorazepam $30 \mathrm{mg}$, clorazepate $100 \mathrm{mg}$ and venlafaxine $300 \mathrm{mg}$ daily; morphine and tramadol on demand. The admission blood test showed no coagulation abnormalities: prothrombin time (PT) 13.40 (reference value (RV): 11.0-15.3) $\mathrm{s}$, prothrombin activity (PA) $100.00 \%$ (RV: 
$70.0 \%-120.0 \%$ ), international normalised ratio (INR) 1.00 (RV: $0.8-1.2$ ) and activated partial thromboplastin time (APTT) 35.10 (RV: 29.2-39.0) s.

Multiple treatment adjustments were made. Benzodiazepines and opioids were withdrawn owing to the ongoing abuse. Paliperidone and gabapentin were titrated up to $9 \mathrm{mg}$ and $2400 \mathrm{mg}$ daily, respectively. The patient maintained an oppositional attitude, which led to prolonged bedding. Thus, a prophylactic dose of enoxaparin was administrated daily. After nearly 3 weeks of hospitalisation, the patient was diagnosed with DVT. Coagulation tests showed PT 18.20 (RV: 11.0-15.3) s, PA $60.00 \%$ (RV: $70.0 \%-120.0 \%$ ), INR 1.41 (RV: 0.8-1.2), APTT 39.80 (RV: 29.2-39.0) s and D-dimer (immunoturbidimetry) 3.98 (RV: $0.1-0.5$ ) $\mu \mathrm{g} / \mathrm{mL}$. The Doppler of lower limbs showed DVT at the left common femoral, the left external iliac and the left common iliac veins. A computed tomography (CT) of the pulmonary artery ruled out PE. Enoxaparin was raised to $70 \mathrm{UI} / 12$ hours.

No progress was achieved after a month, with the patient developing catatonic symptoms, such as immobility, mutism, negativism, posturing and stereotypies. She suffered complications owing to prolonged bedding, such as infections, autonomic dysfunction, urinary retention and constipation. Nasogastric tube placement was required to ensure nutrition and medication. In the absence of improvement, and owing to recurrent urinary retention, paliperidone was suspended. Gabapentin was also withdrawn; venlafaxine and mirtazapine were maintained and lorazepam was started up to $9 \mathrm{mg}$ per day. Since benzodiazepines were not effective, ECT was considered. Owing to the theoretical risk of bleeding and $\mathrm{PE}$, the case was consulted with internal medicine and neurology specialists. The patient underwent both a cranial CT scan and an MRI. No significant abnormalities were found (see online supplemental material 1). Enoxaparin was replaced by bemiparin 7500 UI once daily. After obtaining valid informed consent from the patient's husband, bilateral ECT was started. General anaesthesia was induced by intravenous propofol (100-200 mg) and myorelaxation by succinylcholine $(50-75 \mathrm{mg})$. Bemiparin was administered not less than 18 hours before each ECT session and at least 6 hours after, to prevent the risk of bleeding. The stimulus settings were based on the age and the length of seizures, measured by electroencephalogram, up to a maximum charge of $425.6 \mathrm{mC}(85 \%)$.

After the third administration, the patient showed improvement. She was awake, communicative and cooperative. She started oral intake and walking. She showed self-limited temporary disorientation and amnesia of the episode. A total of seven ECT sessions were carried out without major bleeding or PE. Before discharge, the patient was oriented in all areas. The episodic amnesia was partially maintained but possibly related to the catatonia itself, rather than to the ECT. No other cognitive side effects were observed.
The patient was discharged after 3 months without psychotic or mood symptoms. She maintained certain anxiety and chronic somatisations. She was diagnosed with histrionic personality disorder, unspecified dissociative disorder, and benzodiazepine and opioid dependence according to the International Statistical Classification of Diseases and Related Health Problems, 10th Edition. Treatment at discharge was venlafaxine 225 $\mathrm{mg}$, mirtazapine $30 \mathrm{mg}$, trazodone $100 \mathrm{mg}$, pregabalin 50 $\mathrm{mg}$, olanzapine $7.5 \mathrm{mg}$ and bemiparin $7500 \mathrm{UI}$ daily. The coagulation blood test at discharge showed PT 12.90 (RV: 11.0-15.3) s, PA $100.00 \%$ (RV: $70.0 \%-120.0 \%$ ), INR 1.00 (RV: 0.8-1.2), APTT 31.80 (RV: 29.2-39.0) s.

After hospitalisation, the patient was followed up at the Mental Health Centre and the Community Social Support Team for 1 year, showing improvement. She has not presented any further admissions. At the end of 2020, the patient was lost to follow-up. At this time, she maintained somatic complaints and anxiety related to agoraphobia. She did not present any other affective or psychotic symptoms.

\section{DISCUSSION}

The use of ECT in patients with venous thromboembolism (VTE) and anticoagulant treatment is still a debated topic. Although cases of PE in patients with previous DVT who have undergone ECT sessions have been reported, ${ }^{25}$ the risk remains unclear. Some authors suggest that muscle contractions during a seizure can dislodge a clot from residual DVT, despite the use of succinylcholine, therefore increasing the risk of PE. ${ }^{6-8}$ Nonetheless, several reports show that ECT can be performed safely without major complications in patients with prior DVT. ${ }^{245}$

It has been suggested that there may be an association between the location of the residual DVT and the onset of PE. ${ }^{257}$ In a recent case series, various patients with distal DVT and anticoagulant treatment received ECT without complications. Meanwhile, a patient suffering proximal DVT developed PE one day after the second ECT session. ${ }^{2}$ On the other hand, several cases of proximal DVT have safely undergone ECT treatment, ${ }^{24}$ as happened with our patient. Given the inconsistency, it has been recommended that anticoagulation should be continued until the resolution of proximal DVT, before going through the ECT sessions safely. ${ }^{27}$ ECT is also safe in patients with PE, after proper stabilisation of the medical conditions and initiation of anticoagulant treatment. ${ }^{89}$

Concerns about intracerebral haemorrhage have been raised regarding the use of ECT in patients undergoing anticoagulant therapy since ECT increases momentarily systemic and intracerebral blood pressure. ${ }^{10}{ }^{11}$ In this context, the safety of ECT during the administration of anticoagulant therapy has been reported. ${ }^{2} 45710-14$ However, two matters should be taken into consideration: the dosage and the type of anticoagulant. While 
an overdose may induce an intracerebral haemorrhage during ECT, suboptimal anticoagulation can contribute to the recurrence of thrombosis. ${ }^{12}$ Regarding the type of anticoagulant, some data demonstrate the safety of treatment with heparin, ${ }^{241214}$ as well as with warfarin, ${ }^{11}$ while undergoing ECT. A case series of 35 patients, who had undergone a total of 300 ECT sessions while receiving long-term warfarin treatment, showed no intracerebral haemorrhage despite increases in blood pressure and pulse rate. ${ }^{11}$ However, some authors recommended the use of heparin instead of warfarin, owing to its shorter half-life, which allows its transitory discontinuation before each ECT session and its restitution afterward. ${ }^{12}{ }^{14}$ For instance, Suzuki et al interrupted a patient's heparin infusion 2 hours before each ECT session to prevent brain haemorrhage, with good results. ${ }^{12}$ Regarding our patient, the administration time of bemiparin was strictly controlled before and after ECT sessions, to minimise the bleeding risk. In any case, when warfarin or heparin is used, adequate values of INR or APTT, respectively, should be achieved to reduce the risk of bleeding. ${ }^{12}$ Recently, dabigatran, rivaroxaban, apixaban and edoxaban have emerged as direct oral anticoagulants, constituting the optimal first-line treatment for VTE in uncomplicated patients. ${ }^{15}$ They are associated with a slightly lower risk of haemorrhage compared with warfarin; hence they are a convenient alternative of treatment. ${ }^{515}$ Several reports have demonstrated the safety of treatment with these types of anticoagulants. ${ }^{2510131617}$ For instance, a recent case series described eight patients with severe psychiatric conditions who were taking either rivaroxaban, apixaban or edoxaban for DVT. They were successfully treated with ECT, without major bleeding complications. ${ }^{5}$ It is worth noting that no evidence to date reports the optimal duration of anticoagulant treatment before ECT, which should be a focus of attention in further studies.

In conclusion, it is important to address catatonic symptoms as soon as possible to avoid medical complications. This report provides further evidence about the efficacy and safety of ECT in a patient with proximal DVT and anticoagulant treatment with bemiparin. However, the available evidence on this matter is still scarce and mostly consists of case reports or small case series. Controlled studies are necessary to support the use of ECT in patients with VTE and anticoagulation treatment.

Contributors Both authors made a significant contribution to this study and have read and approved its final version. Both authors were involved in the follow-up and treatment of the patient during her admission to the inpatient unit. AP-B obtained informed consent from the patient for the publication of the article. She also carried out the bibliographic search related to the topic and wrote the main part of the article. IS-R completed the bibliographic search and carried out the revision and correction of the text, contributing to the drafting of the article.

Funding The authors have not declared a specific grant for this research from any funding agency in the public, commercial or not-for-profit sectors.
Competing interests None declared.

Patient consent for publication Obtained.

Ethics approval This study does not involve human participants.

Provenance and peer review Not commissioned; externally peer reviewed.

Supplemental material This content has been supplied by the author(s). It has not been vetted by BMJ Publishing Group Limited (BMJ) and may not have been peer-reviewed. Any opinions or recommendations discussed are solely those of the author(s) and are not endorsed by BMJ. BMJ disclaims all liability and responsibility arising from any reliance placed on the content. Where the content includes any translated material, BMJ does not warrant the accuracy and reliability of the translations (including but not limited to local regulations, clinical guidelines, terminology, drug names and drug dosages), and is not responsible for any error and/or omissions arising from translation and adaptation or otherwise.

Open access This is an open access article distributed in accordance with the Creative Commons Attribution Non Commercial (CC BY-NC 4.0) license, which permits others to distribute, remix, adapt, build upon this work non-commercially, and license their derivative works on different terms, provided the original work is properly cited, appropriate credit is given, any changes made indicated, and the use is non-commercial. See: http://creativecommons.org/licenses/by-nc/4.0/.

ORCID iD

Ana Pérez-Balaguer http://orcid.org/0000-0002-2894-4156

\section{REFERENCES}

1 Weiner RD, Reti IM. Key updates in the clinical application of electroconvulsive therapy. Int Rev Psychiatry 2017;29:54-62.

2 Inagawa Y, Saito S, Okada T, et al. Electroconvulsive therapy for catatonia with deep venous thrombosis: a case series. Prim Care Companion CNS Disord 2018;20:18m02286.

3 American Psychiatric Association. Diagnostic and statistical manual of mental disorders. 5th Edition. Arlington: VA, American Psychiatric Association, 2013.

4 Medda P, Fornaro M, Fratta S, et al. A case of deep venous thrombosis following protracted catatonic immobility recovered with electroconvulsive therapy: the relevance for an early intervention. Gen Hosp Psychiatry 2012;34:209.e5-209.e7.

5 Hirata T, Yasuda K, Uemura T, et al. Electroconvulsive Therapy While Receiving OralAnticoagulation for Deep Venous Thrombosis:Report on Eight Cases and a Review of theLiterature. Psychosomatics 2019;60:402-9.

6 Mamah D, Lammle M, Isenberg KE. Pulmonary embolism after ECT. J Ect 2005;21:39-40.

7 Warriach ZI, Shamim SA, Saeed A, et al. Association of the thromboembolic phenomenon with electroconvulsive therapy treatment in schizophrenia with catatonia patient. Cureus 2019;11:e5656.

$8 \mathrm{~J} \mathrm{~B}, \mathrm{~J} \mathrm{~A}, \mathrm{~T} \mathrm{M}$, et al. A case report of pulmonary embolism during electroconvulsive therapy and its further application after somatic stabilization. Brain Stimul 2020;13:250-2.

9 Dean J, Coconcea C. Electroconvulsive therapy in a patient with pulmonary embolism. J Ect 2016;32:e12.

10 Schmidt ST, Lapid MI, Sundsted KK, et al. Safety of electroconvulsive therapy in patients receiving dabigatran therapy. Psychosomatics 2014;55:400-3.

11 Mehta V, Mueller PS, Gonzalez-Arriaza HL, et al. Safety of electroconvulsive therapy in patients receiving long-term warfarin therapy. Mayo Clin Proc 2004;79:1396-401.

12 Suzuki K, Takamatsu K, Takano T, et al. Safety of electroconvulsive therapy in psychiatric patients shortly after the occurrence of pulmonary embolism. J Ect 2008;24:286-8.

13 Shao E, Moore R, Linnane J. Rivaroxaban for treatment of pulmonary embolism while receiving electroconvulsive therapy. J Ect 2017;33:e25-6.

14 Alexopoulos GS, Nasr H, Young RC, et al. Electroconvulsive therapy in patients on anticoagulants. Can J Psychiatry 1982;27:46-8.

15 Kruger PC, Eikelboom JW, Douketis JD, et al. Deep vein thrombosis: update on diagnosis and management. Medical Journal of Australia 2019;210:516-24.

16 Centanni NR, Craig WY, Whitesell DL, et al. Safety of ECT in patients receiving an oral anticoagulant. Ment Health Clin 2021;11:254-8.

17 Hirata T, Yasuda K, Uemura T, et al. Electroconvulsive therapy in patients with cerebral aneurysms taking an anticoagulant or antiplatelet-report on three cases and review of the literature. Psychiatry Res 2020;288:113022. 


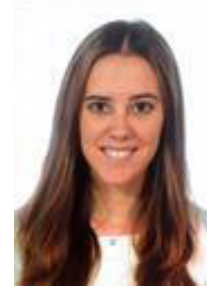

Ana Pérez-Balaguer graduated in medicine from the Universidad Autónoma de Madrid in 2017 and she is currently studying for a master's degree in integrative psychotherapy at the University of Alcalá in Spain. At present, she is developing her professional and training activity as a fourth-year Internal Resident Doctor at the Psychiatric Department of the Hospital Universitario Puerta de Hierro de Majadahonda, Madrid, Spain. In addition, she enrolled in the PhD programme at the Universidad Autónoma de Madrid in June 2021. Her main research interest includes the role of impulsivity in a suicidal population. 